\title{
Spatial Crop Mapping and Accuracy Assessment Using Remote Sensing and GIS in Tawa Command
}

\author{
S. Nema ${ }^{1 *}$, M.K. Awasthi ${ }^{2}$ and R.K. Nema ${ }^{3}$ \\ ${ }^{1}$ National Institute of Hydrology, Roorkee-247667, India \\ ${ }^{2}$ Department of soil and Water Engineering, ${ }^{3}$ Department of soil and Water Engineering, \\ J.N.K.V.V., Jabalpur-482004, India \\ *Corresponding author
}

\section{A B S T R A C T}

\begin{tabular}{|l|}
\hline K e y w o r d s \\
$\begin{array}{l}\text { Remote sensing, GIS, } \\
\text { Crop map, Crop } \\
\text { classification }\end{array}$ \\
\hline Article Info \\
\hline $\begin{array}{l}\text { Accepted: } \\
20 \text { April } 2018 \\
\text { Available Online: } \\
\text { 10 May } 2018\end{array}$ \\
\hline
\end{tabular}

\section{Introduction}

Agriculture is a primary source of food production of mankind's and plays the key role for supply food to humanity. One of the future challenges will be to feed a constantly growing population, which is expected to reach more than nine billion by 2050 (United nations, 2014). This will lead to an increasing demand for food, feed, fiber, which only can be met by boosting agricultural production to achieve self-sustainability (Foley et al., 2011). Critically the potential to expand cropland is limited and changes in the climate system can further amplify the future burden on freshwater resources, e.g., this is quite urgent and crucial to planning for future sustainability as trends suggesting a serious demand for reliable, precise and comprehensive agricultural intelligence on agriculture crop production.

Agricultural production monitoring through remote sensing and GIS can support decisionmaking and prioritization efforts towards sustainable vulnerable parts of agricultural systems. The value of satellite Earth Observation [EO] data in agricultural monitoring is well recognized (Pachauri et al., 2007) and a variety of methods have been developed in the last decades to provide However, categorical monitoring of spatial agricultural production requires frequently 
updated information on the total area under cultivation and intermittently the spatial distribution of crops as input (Ozdogan et al., 2010 and Atzberge, 2013). This insight needs for evolving precise and effective methods to map and monitor the distribution of crop types through crop mapping. Monitoring crop conditions and food production from local to global scales is at the heart of many modern economic, geostrategic and humanitarian concerns. Remote sensing is a valuable resource for spatial agricultural monitoring as well as crop production as it provides valuable information of spatial distribution of crops, crop water requirement and information about crop growth/heath/yield especially for systems relying on satellite EO to monitor agricultural resources (Ozdogan et al., 2010 and Atzberge, C., 2013). The traditional way to retrieve such crop maps is by classifying an image, or a series of images, using one of the widely known classifier concepts and algorithms that are currently available (Tso, B. and Mather, P.M., 2009). In recent past there were many studies conducted to investigate the crop area, yield, land suitability and water resource investigation in perspective of agriculture development, monitoring and future sustainability (Carfagna and Gallego, 2005; Gallego et al., 1993; Justice et al., 2007; Rosenfield and Fitzpatrick Lins, 1986). Due to the immense importance of remote sensing and GIS, The present study was carried for spatial Crop Mapping to study the spatial distribution of crops and its accuracy assessment forTawa Command (Nema et al., 2016; Nema et al., 2017).

\section{Materials and Methods}

\section{Study area}

The Tawa command, having an area of 240000 ha, lies in Hoshangabad district of Madhya Pradesh, India, was selected as study area for current research. Tawa River is the main river of Hoshangabad apart from Narmada River, which is flowing towards north and joins river Narmada near Hoshangabad. The annual normal rainfall in the district is $1225.9 \mathrm{~mm}$. About $92 \%$ of the annual rainfall is received from southwest monsoon.

The procedural progress for the classification was accomplished in three steps.

Ground truth data was collected from agricultural field.

Digital image classification was done

Verification, accuracy assessment and Final refinement on mapping were involved.

\section{Data acquisition}

The satellite image was acquired from https://earthexplorer.usgs.gov/ dated on 8th February 2015. The Survey of India topo sheets were taken as supplementary data on scale of 1:250000 and used for the image processing and classification. The Satellite data details used in the study are given in Table 1.

\section{Preparation of crop map}

The acquired satellite image was interpreted using both digital and visual methods. The composite image was verified thoroughly in order to select the best band combination. [RGB] combination 1-2-3 was used for The False Color Composite [FCC] image (Fig. 2). Classification scheme defines the crop classes were considered for remote sensing image classification. The different crops on season based maps were categorized by Crop classification system. In order to develop crop map using satellite data, NRSC has establish the standard procedural guideline. The four crop classes were selected in current study 
which was wheat, gram, sugarcane, and other crops.

\section{Methodology of supervised classification}

Supervised classification is most popular and widely used quantitative analysis procedure of remote sensing data; it depends upon using appropriate algorithms to label the pixel in an image as representative of particular ground cover types or classes.

Selecting samples or training fields is an essential step in supervised classification. The process involved selections for the pixels, which represent the different patterns based on the requirements. Then supervised classification is done with parametric setting applied to maximum likelihood and it yields great result. The Maximum Likelihood is defined as the classification of pixels on the basis of probability that a pixel belongs to a specific class, assuming that probabilities are equal for all classes and that the input band have normal distribution. Image classification process is presented in Figure 3.

\section{Classification accuracy assessment}

To decide the accurateness of supervised classification, a sample of test pixels were selected on the classified image and their class identity was compared with the reference data [ground truth]. The choice of a suitable sampling scheme and the determination of an appropriate sample size for testing data play a key role in the assessment of classification accuracy (Arora and Agarwal, 2002).

Further, an error matrix was compiled for pixels of agreement and disagreement, which is generally in the form of a c x c matrix [c is the number of classes], the elements of which indicate the number of pixels in the test data. The columns of the matrix show the number of pixels per class for the reference data, and the rows show the number of pixels per class for the classified image. From this error matrix, a number of accuracy measures such as overall accuracy, user's and producer's accuracy, may be determined (Congalton, 1991). The overall accuracy represents the accuracy of whole classification [i.e. number of correctly classified pixels divided by the total number of pixels in the error matrix], whereas the other two measures indicate the accuracy of individual classes.

A probability that a pixel classified on the map actually regarded as user's accuracy as on the ground or on the reference data, whereas producer's accuracy represents the probability that a pixel on reference data has been correctly classified. Accuracy has been measured by comparing classified crop map with FCC using control point. There were total 200 points were specified in stratified random method, the process selects the random point from each class separately [the classes are weighted in a different way; hence the number of sample data points vary from one class and another. Then the class value is assigned using "class value assignment option" and center value as the no majority option is used. Later, each point of crop type is identified by interpreting the underlying image. The report is generated which produces overall accuracy, user accuracy, producer accuracy and error matrix.

\section{Results and Discussion}

\section{Crop classification}

The result of classification is shown in the Figure 4 which represents different crop classes i.e., wheat, gram, sugarcane and other crops. Wheat crop was having the maximum area [84.90\%] and gram crop was having [10.23\%] area and other crop showing the minimum rest of the area. The most prevailing crop from crop classes was found as wheat for 
Hoshangabad which covers 2264902 ha, followed by gram [31895 ha], sugarcane [6025.6 ha] and other crops [8857.6 ha].

\section{Classification accuracy assessment report}

For many analytical statistical techniques, an error matrix is an appropriate beginning, especially in discrete multivariate techniques. Discrete multivariate techniques are appropriate because remotely sensed data are discrete rather than continuous. The data are also binomially or multinomial distributed, and therefore, common normal theory statistical techniques do not apply (Jensen, 1996).

KAPPA is a discrete multivariate technique developed by Cohen (1960) and has been applied for crop accuracy assessment derived from remotely sensed data (Congalton and
Mead, 1983; Rosenfield and Fitzpatrick Lins, 1986; Gong and Howarth, 1990). The result of performing a KAPPA analysis is the KHAT statistic [an estimate of KAPPA] which is another measure of accuracy or agreement. Values of KAPPA greater than 0.75 indicate strong agreement beyond chance, values between 0.40 and 0.79 indicate fair to good, and values below 0.40 indicate poor agreement (SPSS Inc., 1998). Overall accuracy uses only the main diagonal elements of the error matrix, and, as such, it is a relatively simple and intuitive measure of agreement. On the other hand, because it does not take into account the proportion of agreement between data sets that is due to chance alone, it tends to overestimate classification accuracy (Congalton and Mead, 1983; Rosenfield and FitzpatrickLins, 1986; Ma and Redmond, 1995).

\section{Table.1 Details of Satellite Image used for the study}

\begin{tabular}{l|l|l|l|l|} 
S. No. & Satellite & Spatial Resolution $(\mathrm{m})$ & Year & Source \\
\hline $\mathbf{1}$ & Landsat-8 & 30 & 8th February, 2015 & https://earthexplorer.usgs.gov/ \\
\hline
\end{tabular}

Table.2 Cropped feature and their respective area over the study area

\begin{tabular}{|c|c|}
\hline Crop Feature & Total Area (ha) \\
\hline Wheat & 264902.0 \\
\hline Gram & 31895.2 \\
\hline Sugarcane & 6025.59 \\
\hline Other Crops & 8857.62 \\
\hline
\end{tabular}

Table.3 Classification accuracy error matrix for the crop map using reference data (ERROR MATRIX)

\begin{tabular}{|c|c|c|c|c|c|}
\hline \multirow[t]{2}{*}{ Classified Data } & \multicolumn{5}{|c|}{ Reference Data } \\
\hline & Wheat & Gram & Sugarcane & Others & Row Total \\
\hline Wheat & 53 & 2 & 4 & 1 & 60 \\
\hline Gram & 3 & 52 & 3 & 2 & 60 \\
\hline Sugarcane & 3 & 1 & 54 & 2 & 60 \\
\hline Others & 2 & 2 & 2 & 14 & 20 \\
\hline Column Total & 61 & 57 & 63 & 19 & 200 \\
\hline
\end{tabular}


Fig.1 Location map of the study area

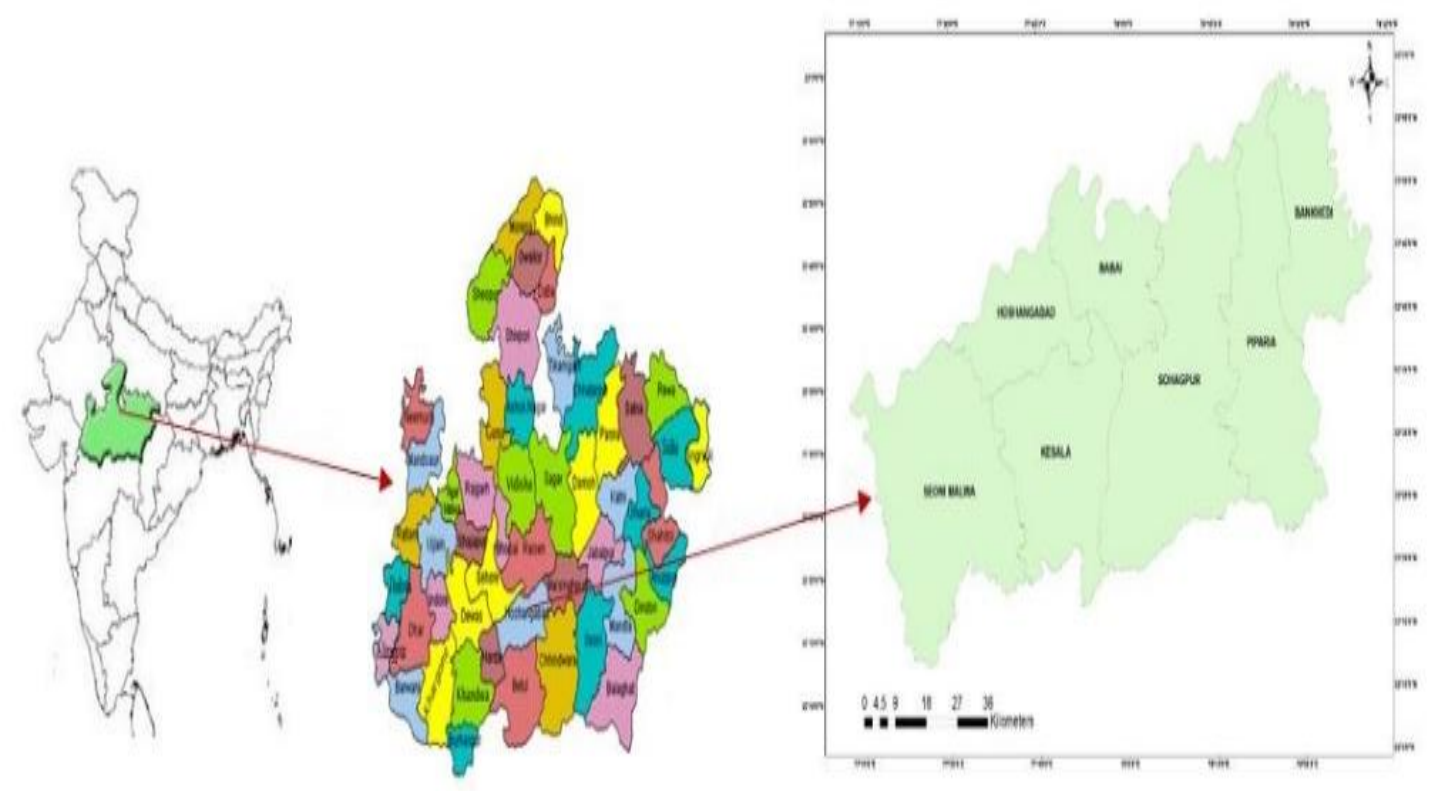

Fig.2 FCC image of study area

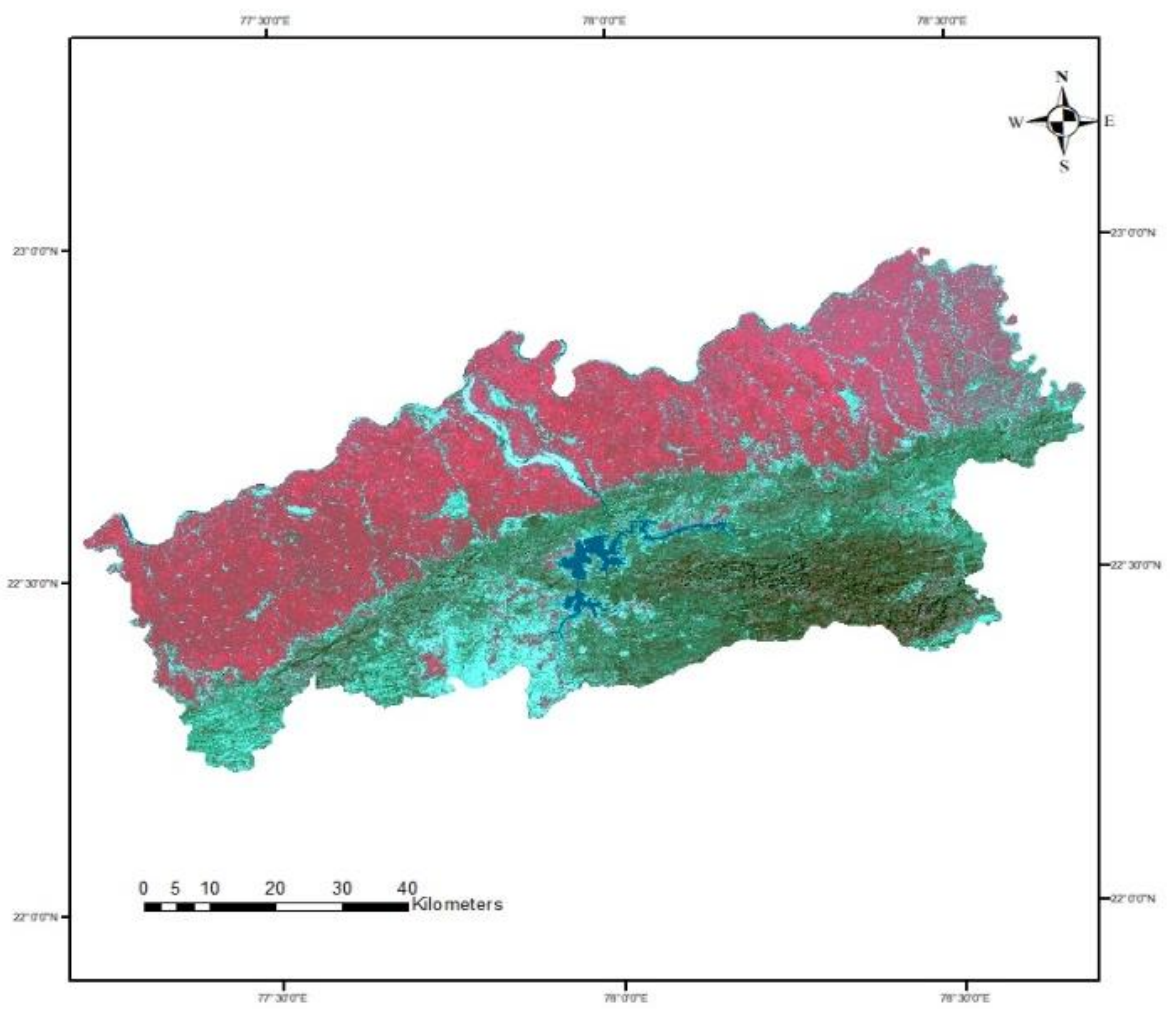


Fig.3 Methodology for crop classification and accuracy assessment

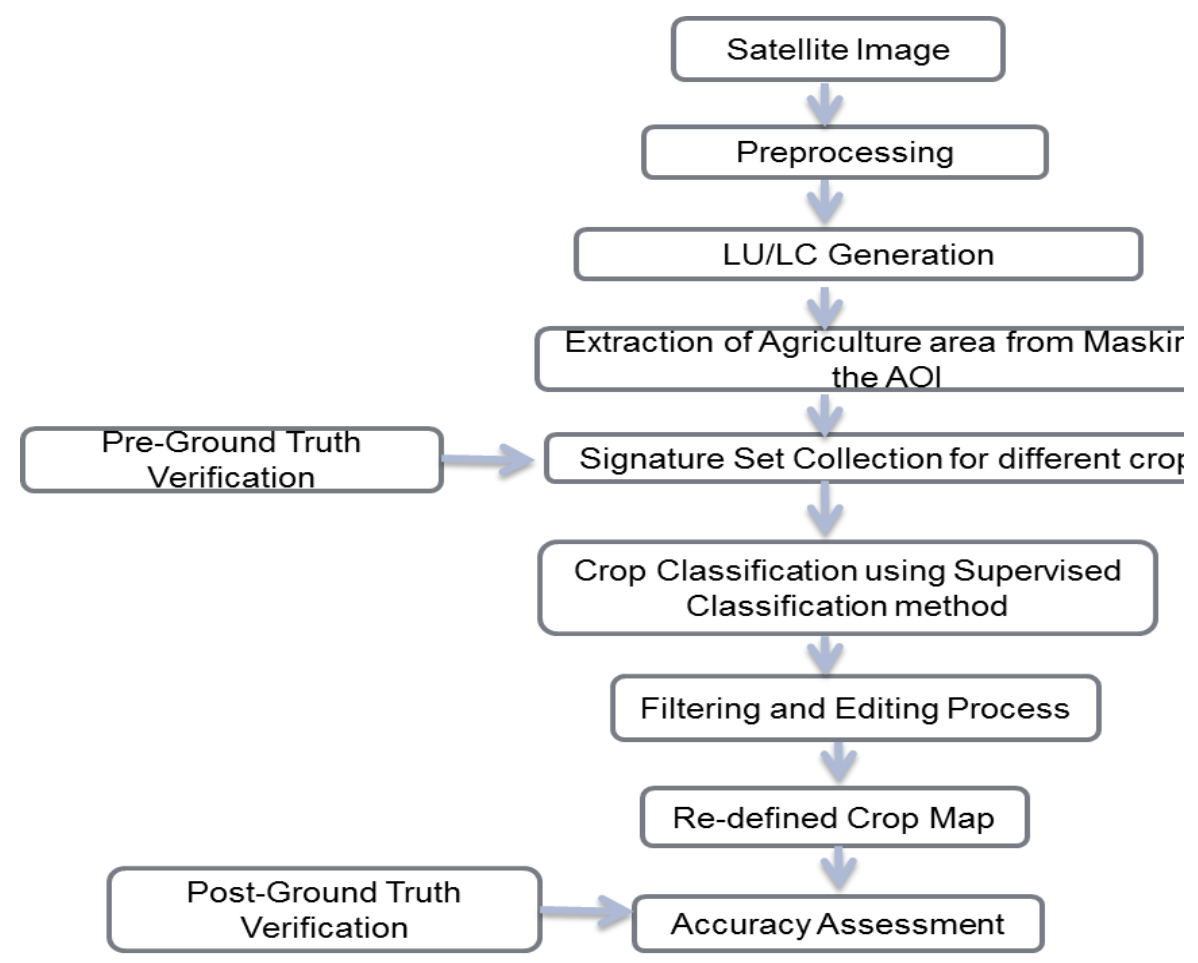

Fig.4 Crop map along with crop features

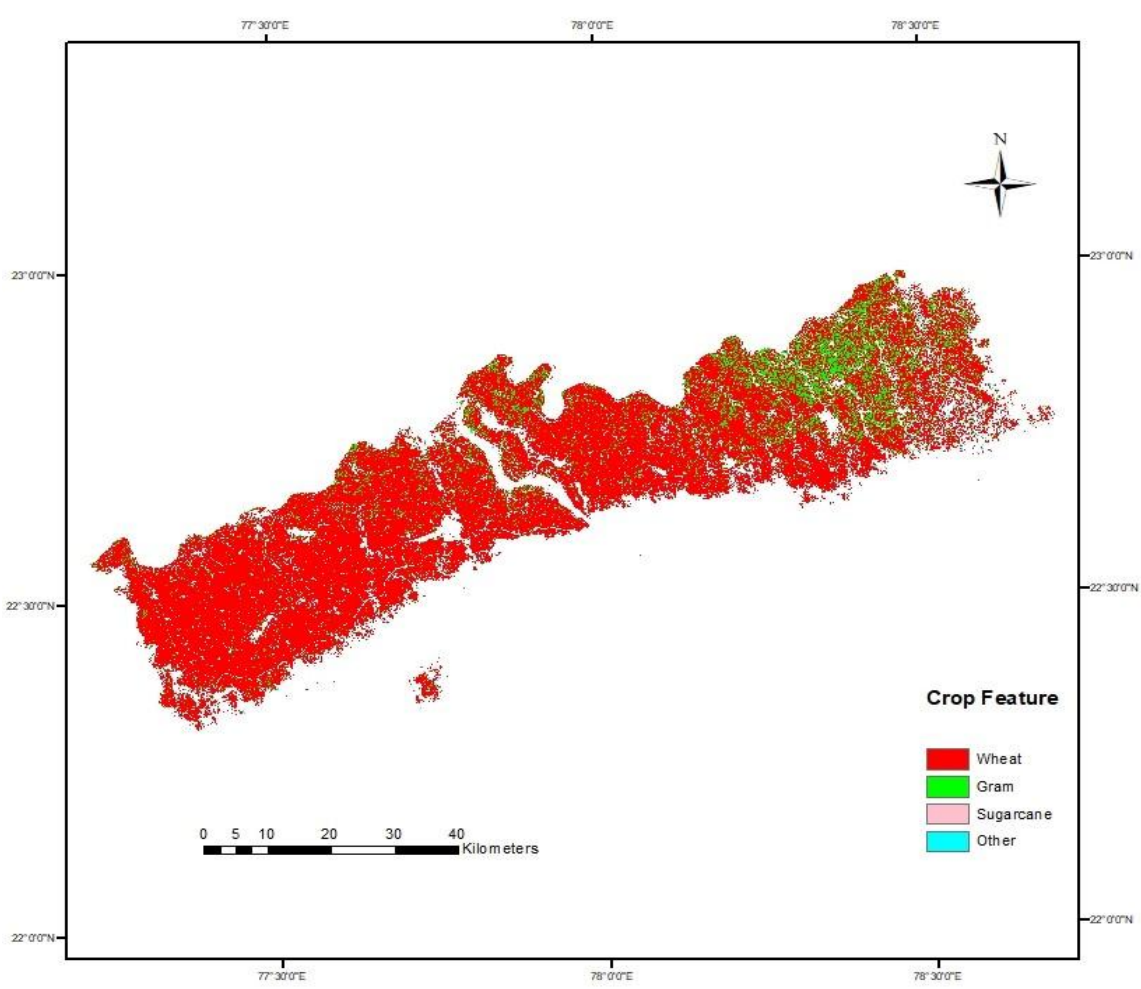


KHAT accuracy assessment process has become very popular and widely used because it attempts to control for chance agreement by incorporating the off-diagonal elements as a product of the row and column marginal of the error matrix. Theoretically, $\mathrm{k}$ can be defined as:

$k=\frac{\text { (observedaccuracy }- \text { changeagreement })}{(1-\text { changeagreement })}$

The error matrix showing producer's and user's, and overall classification accuracy, and including the Kappa coefficients is shown in Table 3. The matrix of error shows that there are 7 cell which should be classified as wheat but classified as gram, sugarcane and others. There are 8 cells which should be classified as gram but classified as wheat, sugarcane and others. There are 4 cells which should be classified as sugarcane but classified as wheat and gram. There are 8 cell which should be classified as others but classified as wheat, gram and sugarcane. The total accuracy in this classification accuracy is $89.80 \%$, which is showing good agreement between training sites and it also suggest that training test sites which were selected are $89.80 \%$ spectrally separable, and the training areas were classified quite well. Producer's accuracy refers to the how accurately the producer assigned the classes for the training sites. Producer's accuracy is computed by dividing the number of correctly classified pixels by the number of training sites pixels. The producer accuracy for wheat is $88.16 \%$, gram $86.66 \%$, sugarcane $85.71 \%$ and others $70 \%$. User's accuracy refers to the accuracy that the pixel categorized in a certain class is truly representing that class on the ground. User's accuracy is calculated by dividing the number of correctly classified pixels by the total number of pixels that were classified in that class. For wheat user accuracy is $88.33 \%$, gram $85.23 \%$, sugarcane $90 \%$ and others $82 \%$. The overall kappa statistics was found as 0.793
Based on results it can be concluded that Crop mapping to extract spatial features can easily be derived from the satellite imaginary with high degree of accuracy. The classified data of crop can be used in wide variety of domains such as water resource management, efficient policy planning, change detection in cropping pattern, field resource management and economic development, etc. The continued update of crop map type of data is necessary to assess the various aspects related to agriculture. The present status of crop in the Hoshangabad district as evaluated by digital analysis of satellite data indicates that majority of area belongs to wheat crop i.e. which is nearly $85 \%$. The accuracy of assessment shows that overall accuracy is 84.37 percent which is good result and kappa statistics shows 0.793 which shows good agreement between reference and classified image. This study evidently showed that Remote Sensing and GIS is a very innovative tool to provide accurate spatial information on crop cover of a region in a time and cost effective manner.

\section{References}

Arora M.K. and Agarwal K. 2002. A program for sampling design for image classification accuracy assessment. Photogrammetry Journal of Finland, 18(1): 33-43.

Atzberger, C. 2013. Advances in remote sensing of agriculture: Context description, existing operational monitoring systems and major information needs. Remote Sens. 5: 949-981.

Carfagna, E., Gallego, J.F. 2005. Using remote sensing for agricultural stautistics. Int. Stat. Rev. 73, 389-404.

Cohen I. 1960. A coefficient of agreement of nominal scales. Educational and Psychological Measurement, 20(1): 3746. 
Congalton R. and Mead R.A. 1983. Photogrammetric Engineering and Remote Sensing, 49(1): 69-74.

Congalton, R.G. 1991. Remote Sensing of Environment, 37(1): 35-46.

Foley, J.A., Ramankutty, N., Brauman, K.A., Cassidy, E.S., Gerber, J.S., Johnston, M., Mueller, N.D., O'Connell, C., Ray, D.K., West, P.C. 2011. Solutions for a cultivated planet. Nature 478: 337-342.

Gallego, J.F., Delince, J., Rueda, C.1993. Crop area estimates through remote sensing: Stability of the regression correction. Int. J. Remote Sens.14, 3433-3445.

Gong P. and Howarth P. 1990. Photogrammetric Engineering and Remote Sensing, 56(5): 597-603.

Jensen J.R. 1996. Introductory Digital Image Processing. A Remote Sensing Perspective, Upper Saddle River, New Jersey: Prentice Hall.

Justice, C., Becker-Reshef, I. 2007. Report from the Workshop on Developing a Strategy for Global Agricultural Monitoring in the Framework of Group on Earth Observations (GEO); University of Maryland: College Park, MD, USA, p 67.

Ma Z. and Redmond R.L. 1995. Photogrammetric Engineering and Remote Sensing, 61(4): 435-439.

Nema Sourabh, Awasthi M.K., Nema R.K. 2016. Trend Analysis of Annual and Seasonal Rainfall in Tawa command Area. International Journal of Environment, Agriculture and
Biotechnology (IJEAB), Vol-1(4): 0952-0957

Nema, Sourabh, Awasthi, M.K., Nema R.K. 2017. Spatial and temporal ground water responses to seasonal rainfall replenishment in an alluvial aquifer. Bioscience and Biotechnology Communications, 10(3): 431-437 (2017)

Ozdogan, M., Yang, Y., Allez, G., Cervantes, C. 2011. Remote sensing of irrigated agriculture: Opportunities and challenges. Remote Sens. 2010 (2): 2274-2304.

Pachauri, R.K., Reisinger, A. 2007. Climate Change 2007: Synthesis Report. Contribution of Working Groups I, II and III to the Fourth Assessment Report of the Intergovernmental Panel on Climate Change; IPCC: Geneva, Switzerland, 2008; p 104.

Rosenfield G.H. and Fitzpatrick Lins K. 1986. Photogrammetric Engineering and Remote Sensing, 52(2), 223-227.

SPSS Inc. 1998. SYSTAT - 8.0, Chicago, Illinois.

Tso, B., Mather, P.M. 2009. Classification Methods for Remotely Sensed Data, 2nd ed.; CRC Press Taylor and Francis Group: Boca Raton, FL, USA/London, UK/New York, NY, USA.

United Nations. 2014. World Urbanization Prospects-The 2014 Revision: United Nations: New York, NY, USA, 2014. Pp. 32.

\section{How to cite this article:}

Nema, S., M.K. Awasthi and Nema, R.K. 2018. Spatial Crop Mapping and Accuracy Assessment Using Remote Sensing and GIS in Tawa Command. Int.J.Curr.Microbiol.App.Sci. 7(05): 3011-3018. doi: https://doi.org/10.20546/ijcmas.2018.705.350 